\title{
Phylogenetic Investigation of the Aliphatic, Non- hydrolyzable Biopolymer Algaenan, with a Focus on Green Algae
}

\section{Citation}

Kodner, Robin B., Roger E. Summons, and Andrew H. Knoll. 2009. Phylogenetic investigation of the aliphatic, non-hydrolyzable biopolymer algaenan, with a focus on green algae. Organic Geochemistry 40(8): 854-862.

\section{Published Version}

doi:10.1016/j.orggeochem.2009.05.003

\section{Permanent link}

http://nrs.harvard.edu/urn-3:HUL.InstRepos:3822893

\section{Terms of Use}

This article was downloaded from Harvard University's DASH repository, and is made available under the terms and conditions applicable to Open Access Policy Articles, as set forth at http:// nrs.harvard.edu/urn-3:HUL.InstRepos:dash.current.terms-of-use\#OAP

\section{Share Your Story}

The Harvard community has made this article openly available.

Please share how this access benefits you. Submit a story.

\section{Accessibility}


Phylogenetic investigation of the aliphatic, non-hydrolyzable biopolymer algaenan, with a focus on the green algae

Robin B. Kodner ${ }^{a^{*}}$, Roger E. Summons ${ }^{b}$, Andrew H. Knoll ${ }^{c}$

${ }^{a}$ University of Washington, School of Oceanography and Friday Harbor Labs, Friday Harbor, WA 98250 , U.S.A

${ }^{\mathrm{b}}$ Massachusetts Institute of Technology, Department of Earth and Planetary Sciences, Cambridge, MA 02139, U.S.A.

${ }^{\mathrm{c}}$ Harvard University, Department of Organismic and Evolutionary Biology, Cambridge, MA 02138, U.S.A.

*Corresponding author. E-mail address: rkodner@u.washington.edu (Robin Kodner).

Key Words: algaenan; algae; phylogeny; kerogen

\section{ABSTRACT}

Algaenan, an aliphatic biopolymer found in various microalgae, has been implicated as the source of a sizable proportion of the aliphatic refractory organic matter in sedimentary rocks.

Because of its recalcitrant nature, algaenan is thought to be preserved selectively in the formation of kerogen and microfossils. The taxonomic distribution of algaenan in living organisms has not been studied in detail or in a phylogenetic context. Here, we evaluate the distribution and phylogenetic relationships of algaenan-producing organisms from a broad, eukaryote-wide perspective down to the level of genus and species. We focus on the kingdom Plantae, as most described algaenan producers belong to this superkingdom. The phylogenetic distribution of algaenan producers within the Plantae is actually quite limited and a detailed phylogenetic analysis of the two classes that include all green algal algaenan producers suggests that there is no finer-grained pattern of phylogenetic distribution to the production of this biopolymer. Our results suggest that the algaenan biopolymer is not widespread ecologically or phylogenetically, is not found abundantly in marine organisms, and likely represents a functional description of molecular class, ra- 
ther than a biomarker for green algae. This adds to a growing body of literature that questions the selective preservation hypothesis for insoluble organic matter and calls for a more detailed chemical and structural analysis of algaenan.

\section{Introduction}

\subsection{Algaenan as a geomacromolecule and a biopolymer}

Algaenan is a non-hydrolyzable, insoluble biopolymer (Tegelaar et al., 1989) that has been isolated from a variety of unicellular algae and is recognized as an important component in kerogen, the largest organic carbon sink on the planet (Berner, 1989; Hedges, 1995). Despite the importance of kerogen in the organic carbon cycle, its synthesis incompletely understood. The discovery of an algaenan-like signature in kerogens associated with algal microfossils (Derenne et al., 1994; Derenne et al., 1992; Goth et al., 1988) led to the hypothesis that the preferential preservation of algaenan and other recalcitrant biopolymers plays a principal role in kerogen formation (Derenne et al., 1991; Gelin et al., 1996; Tegelaar et al., 1989).

Recently, a number of taphonomic studies have begun to question the selective preservation hypothesis. Taphonomic research on arthropod and leaf cuticles suggests that diagenesis creates an aliphatic signature in structures whose original composition was not aliphatic (Briggs et al., 1995; de Leeuw, 2007; Gupta et al., 2006a). Another taphonomic experiment showed that soluble hydrocarbons in vegetable oil can generate an aliphatic signature like that of kerogens or biopolymers when exposed to conditions encountered during diagenesis (Versteegh et al., 2004). Additionally, it has been shown that some kerogens with an aliphatic signature were predominantly sourced by organisms that do not produce aliphatic biopolymers, implying the aliphatic material formed during diagenesis and should be considered a geopolymer 
(Kuypers et al., 2002). Together, these results suggest that the formation of an aliphatic signature in kerogens and fossils is more complex than the simple selective preservation of specific biopolymers, as concluded earlier (de Leeuw, 2007; Gupta et al., 2007b) and references cited herein). The strongest evidence that biologically produced aliphatic biopolymer could be a source of aliphatic signatures in kerogens and microfossils is the observed presence of an aliphatic biopolymer in certain microalgae.

Although algaenan is indisputably an important chemical constituent of some unicellular photosynthetic organisms, current understanding of both its chemical nature and biological function is filled with ambiguities and uncertainties. In large part, this reflects difficulties encountered in the isolation, purification and characterization of this complex material. The structure of macromolecular compounds such as algaenan cannot be fully elucidated using conventional analytical methods. Analysis is has traditionally been restricted to techniques that yield information about the overall chemical nature of the biopolymer, such as Fourier transform infrared spectrometry (FTIR) or nuclear magnetic resonance $\left({ }^{13} \mathrm{C} N \mathrm{NR}\right)$, but do not provide an exact molecular composition. Pyrolysis-gas chromatography-mass spectrometry (py-GC-MS) has been widely used to evaluate the molecular entities comprising algaenan, but there are many aspects of the overall structure that this method cannot address, though some progress has been made using thermal decomposition models (Salmon et al., 2009; Salmon et al., 2008). Metzger et al. (2007) combined pulse-field gradient NMR analysis and classical chemistry to infer that algaenan from Botryococcus braunii strain B is formed by intermolecular condensation of aliphatic polyunsaturated dialdehydes with triterpene diol (B-race), or tetraterpene diol (L-race) moieties (Metzger et al., 2007). The polyaldehydes, themselves, originate from polymerization of diunsaturated $\alpha, \omega$-dialdehydes via an aldolization-dehydration mechanism (Metzger et al., 
2008). Some structural information has also come from chemical degradation using $\mathrm{RuO}_{4}$ (Blokker et al., 2006; Blokker et al., 1998; Schouten et al., 1998), trimethyammonium hydroxide (TMAH) and TMAH thermochemolysis (Allard and Templier, 2000; Blokker et al., 1998) and HI (Blokker et al., 1998). At present, however, the unifying character for the biopolymers classified as algaenan remains their aliphatic nature, long carbon chains and resistance to chemical and biological attack.

Biological investigations of the physiology, function and phylogenetic distribution of algaenan have also been limited. Algaenan has been isolated from the cell walls of chlorophycean algae from the genera Scenedesmus, Tetraedron, Chlorella (Allard et al., 2002; Goth et al., 1988), Botryococcus (Templier et al., 1992; Metzger et al., 2008), and Haematococcus (Montsant et al., 2001). Many of these genera have cell walls with a tri-laminar structure (TLS), though not all TLS-containing algae produce algaenan and not all algaenanproducing taxa have TLS (Allard et al., 2002). Beyond this ultrastructural feature, no other morphological traits seem to correlate with algaenan production or unite algaenan producers. Algaenan has also been identified in the zyogspores of Chlamydomonas monica (Blokker et al., 1999), the aplanospores of Dunaniella sp., and the akinetes of Haematococcus pluvialis (Blokker, 2000), but no other resistant algal cysts or reproductive structures have been shown to be aliphatic in nature. Connections have also been drawn between putative algal fossils and algaenan, but the cell walls of modern analogs for the fossils in question -- the phycomata of Halosphaera, do not contain algaenan, calling such a correlation into question (Kodner, 2007).

\subsection{Distribution of algaenan-producing organisms}

Reviews have compiled the literature on occurrences of algaenan and other nonhydrolyzable insoluble biopolymers (de Leeuw et al., 2006; Versteegh and Blokker, 2004); 
however, there has not been a broad scale phylogenetic assessment of algaenan-producing organisms. To date, algaenans have been reported from green algae, eustigmatophytes, and a single dinoflagellate (Versteegh and Blokker, 2004) -- groups that doubtfully have a common ancestor that itself synthesized algaenan.

To understand further how algaenan is distributed among eukaryotes, we have focused on the group in which the biopolymer is most abundant and diverse: the green algae. Green algae are part of a eukaryotic kingdom called the Plantae (Cavalier-Smith, 1998) or the Archeoplastida (Adl et al., 2005) that is strongly supported in most phylogenies. This clade originated with the primary endosymbiotic event between a protist and a cyanobacterium that introduced photosynthesis to the Eukarya (Keeling et al., 2005), and displays impressive diversity in cellular structure, physiology and ecology. Other groups of algaenan produces, eustigmatophytes and dinoflagellates have a much different evolutionary history. To investigate the distribution and evolutionary history of algaenan production in the Archeoplastida, we assayed algaenan production in representatives of the three major subgroups of this clade: the green, red and glaucocystophyte algae.

\section{Methods}

\subsection{Biomass}

Algae (Table 1) were grown in batch cultures in large flasks (2 or 4 L Erlenmeyer flasks or $2 \mathrm{~L}$ Fernbach flasks) under air lift conditions under $24 \mathrm{~h}$ of light. All cultures were grown under the same temperature and light regime and on the Bolds Basal Media (BBM), all being freshwater or terrestrial strains. Cultures were harvested at the end of log phase. Acrochaetium (a macroscopic alga), Coleochaete succata, Compsopogon sp?, Chlamydomonas reinhardtii and Chlorella 
vulgaris were supplied by Carolina Biological Supply. Cyanophora paradoxa (LB 555), Glaucocystis nostocinearum (64) and Klebsormidium flaccum (LB 1958) were supplied by the University of Texas Culture Collection (UTEX). Scenedesmus bajacalifornica, Cylindrocystis brebesonii (LG2 VF30), Bracteococcus sp? (BC2-1), Chlorosarcinopsis gelatinosa (SEV2-VF1) were generously supplied by L. Lewis and Z. Cardon from the Biotic Crusts project. Chlorococcidiopsis sp? (CCMEE 171), Chlorosarcinopsis sp? (CCMEE 174), and Stichiococcus $s p ?(170)$ were supplied by the Culture Collection of Microbes in Extreme Environments. Pycnococcus sp? (CCMP 1998), Dixonella grise (CCMP1916), and Cyanophora paradoxa (CCMP329) were supplied by the Provasoli-Guillard Culture Collection of Marine Phytoplantkon (CCMP).

\subsection{Algaenan extraction}

Extraction was preformed as described by Allard et al. (1998) and was optimized to be as artifact free as possible. Lyophilized biomass was extracted once with hexane, $\mathrm{CHCl}_{3}$, and $\mathrm{CHCl}_{3}: \mathrm{CH}_{3} \mathrm{OH}(1: 1)$. Lipid free biomass was then hydrolyzed $(2 \mathrm{x})$ with $2 \mathrm{~N}$ trifluoroacetic acid (TFAA) at $100{ }^{\circ} \mathrm{C}$ for $3 \mathrm{~h}$, followed by hydrolysis in $4 \mathrm{~N}$ and $6 \mathrm{~N} \mathrm{TFAA}$ at $100^{\circ} \mathrm{C}$ for $18 \mathrm{~h}$. After each hydrolysis, the residual biomass was filtered from the supernatant and washed with hot water until there was no evidence of sugar. Sugar was assayed using a colorimetric test for polysaccharides. Phenol $(0.1 \mathrm{ml}, 80 \%)$ and conc. $\mathrm{H}_{2} \mathrm{SO}_{4}(0.5 \mathrm{ml})$ were added to $0.2 \mathrm{ml}$ of wash solution. Sugars in solution were indicated by a yellow color. The residual biomass was retained on glass filter paper and returned to a Teflon tube for the next hydrolysis step. After the $6 \mathrm{~N}$ TFAA hydrolysis, polysaccharide-free residual biomass was saponified with $5 \% \mathrm{KOH}$ in $\mathrm{CH}_{3} \mathrm{OH}$ under reflux for $1 \mathrm{~h}$, followed by extensive washing with hot water to remove 
polysaccharides liberated by saponification. Residual biomass was again retained on filter paper and returned to a Teflon centrifuge tube for the final $6 \mathrm{~N} \mathrm{HCl}$ hydrolysis at $110{ }^{\circ} \mathrm{C}$ for $24 \mathrm{~h}$.

\subsection{Algaenan analysis}

If no biomass could be recovered at any point in the extraction procedure, we concluded that the organism did not produce algaenan. In questionable cases, filter paper or residual biomass used in extractions was pyrolyzed using py-GC-MS with a CDS Chemical 5100 pyroprobe coupled to a Micromass Autospec Ultima mass spectrometer via a Hewlett Packard 6890 gas chromatograph. GC was performed with a JandW Scientific DB-1MS column (60 m x $0.25 \mathrm{~mm}$ ID, $0.25 \mu \mathrm{m}$ film thickness) using $\mathrm{He}$ as carrier gas. The oven was programmed from $50^{\circ} \mathrm{C}$ (held $1 \mathrm{~min}$ ) to $300^{\circ} \mathrm{C}$ (held $28 \mathrm{~min}$ ) at $8^{\circ} \mathrm{C} \mathrm{min}^{-1}$. The source was operated at $250^{\circ} \mathrm{C}$ in the electron ionization (EI) mode at $70 \mathrm{eV}$ ionization energy. The Autospec scan rate was $0.80 \mathrm{~s} /$ decade over a range of $\mathrm{m} / \mathrm{z} 50$ to 700 with an inter-scan a delay of $0.20 \mathrm{~s}$. Various pyrolysis temperatures were tested $\left(330,400,600,700{ }^{\circ} \mathrm{C}\right)$ and optimized using the algaenan of $B$. braunii as a standard.

\subsection{Phyolgenetic analysis}

A gene tree of the $18 \mathrm{~S}$ small subunit ribosomal RNA gene was made for all organisms tested for algaenan production in this study and in the literature. Strain specific $18 \mathrm{~S}$ sequences for all species investigated for their algaenan production were obtained from GenBank (National Center for Biotechnology Information), if available, or were sequenced in this study. All algaenan and sequence references were verified in original literature and with culture collections databases.

The cross-checking is important because green algae are often misidentified in culture collections when the identification is based on morphology alone, so a specific name does not 
always identify a strain reliably -- this especially true of the genus "Chlorella." Algaenan production may also be strain- rather than species-specific, as demonstrated by the three races of Botryococcus braunii (Bertheas et al., 1999; Gelin et al., 1994; Metzger et al., 2007). See Table 1 for species used in phylogenetic analysis, their strain designation, and accession number.

DNA for phylogenetic analyses was extracted from pelleted cultures. Primers were designed using $18 \mathrm{~S}$ alignments for green algae or were provided by L. Lewis (Shoup and Lewis, 2003). Primer sequences can be found in Table 2. DNA was amplified with the polymerase chain reaction (PCR) and purified for direct sequencing. Alignments of sequences were made using Geneious (Biomatters, 2007) and Jalview (Clamp et al., 2004) and then hand edited with MacClade. Phylogenetic analysis was conducted with maximum likelihood methods, using the PHYLIP sequence package (Felsenstein, 2005) as well as the PHYML online server (Guindon et al., 2005) using the HKY substitution model, 1 substitution rate category and a transition/transversion ratio of 2 or 4 . Varying the substitution model and transition/transversion ratio did not affect tree topology.

\section{Results}

\subsection{Algaenan extraction}

The distribution of algaenan among investigated organisms is summarized in Table 3 . No algaenan production was found outside the Chlorophyceae or Trebouxiophyceae; in extraction of lipid-free biomass from members of the Streptophyta, Rhodophyta, Glaucystophyta and Ulvaphyceae, all biomass was lost at some hydrolysis step. To verify that the biopolymer was not artificially assumed absent as a result of loss of small quantities during extraction, lipid-free biomass was analyzed using py-GC-MS to determine if an aliphatic signature was underpinning 
the total ion current (TIC) or not. No biomass of the 'algaenan-negative' taxa displayed aliphatic compounds that might signal the presence of algaenan.

To verify the extraction procedure, we used two controls: Botryococcus braunii (race L), which has a previously characterized algaenan, and an analysis of biomass after successive hydrolysis of Scenedesmus deserticolata biomass. The extraction of Botryococcus algaenan was similar to that in previous race L algaenan analysis (Behar et al., 1995). Analysis of successive extractions shows that the highly aliphatic nature of the algaenan becomes more pronounced with each hydrolysis as it liberates contaminants bound within the biopolymer matrix (see Fig. 1). This experiment suggests that screening partially extracted biomass will identify molecules of a highly aliphatic nature even in complex matrices. Incomplete extraction may influence interpretation of algaenan characteristics. Algaenan isolated from four species of Scenedesmus, showed the common attribute of aliphatic nature; however, the maximum and dominant chain lengths were variable (Fig. 2).

\subsection{Phylogenetic analysis}

Fig. 3 shows a consensus phylogenetic tree made from analysis of the 18S SSU RNA gene using maximum likelihood with 100 bootstraps. This phylogeny resolves the three families of the Chlorophyta and confirms that algaenan production is limited to the Chlorophyceae and the Trebouxiophyceae. Analysis includes all algaenan-producing strains for which a sequence was available either from GenBank or our sequencing efforts. Because so many non-algaenan producing algae were tested, we used taxonomically informative strains from the literature and chlorophytes used in this study. Though bootstrap support is low for some of the species level relationships, the topology is robust; it was recovered in $20+$ analyses and is in agreement with published phylogenies (Handa et al., 2003; Huss et al., 1999; Senousy et al., 2004). 


\section{Discussion}

Because the algaenans found in distantly related clades doubtfully have a common evolutionary origin, "algaenan" becomes an operational term for aliphatic, non-hydrolyzable biopolymers that have similar chemical features.

\subsection{Phylogenetic patterns of algaenan production in the green algae}

Previously, algaenan was found most commonly within the green algae; thus, the majority of species assayed here come from this division. Green algae are divided into two major groups, which are further subdivided into five classes. Known algaenan producers had been previously limited to two classes (the Chlorophyceae and Trebouxiophyceae) found within one major group, the Chlorophyta. Consistent with previous work, our survey did not find algaenan outside the Chlorophyceae or Trebouxiophyceae (Fig. 3B), even though we surveyed many taxa in the other major clade of green algae, the Streptophyta. The Streptophyta contains the class Charophyceae, a diverse group of freshwater and terrestrial algae that gave rise to the land plants,. No streptophytes have previously been investigated for the presence of algaenan in vegetative tissues. Some Charophyceae, including members of the genera Mougeotia, Spirogyra, and Zygnema have been shown to produce acetolysis-resistant spores, suggesting that they may contain biopolymer (Versteegh and Blokker, 2004). The nature of this polymer is unknown and has not been tied to algaenan. Our sample set also includes a number of liverworts, the earliest diverging land plants (Qiu et al., 2007; Qiu et al., 2006), which have also been shown to produce a acetolysis-resistant biopolymer (Kodner and Graham, 2001; Kroken et al., 1996). Once again, our extractions suggest that this polymer is not algaenan. 
Fig. 3 shows the phylogenetic distribution of algaenan within the Chlorophyceae and the Trebouxiophyceae. The Scenedesmus clade provides an example of a strong, genus-level phylogenetic signal. All strains of Scenedesmus tested prior to this study had been found to produce algaenan, and at least four other algaenan-producing species of Scenedesmus algaenan are not represented in the tree because 18s SSU rRNA sequence or strain information was unavailable. Included in the Scenedesmus clade are two species previously described as Chlorella. The classically applied genus Chlorella is well known to be polyphyletic (Qiu et al., 2007), based on biochemical, morphological and phylogenetic studies, and many species nominally assigned to Chlorella should be reassigned to Scenedesmus based on phylogenetic studies (Huss et al., 1999). Chlorella emersonii CCAP 211-2p and Chlorella marina CCAP 211-27 fall within the Scenedesmus clade in this analysis and, in character with this phylogenetic placement, produce algaenan. Another Chlorella species, Chlorella fusca, has been reinterpreted as a unicellular Scenedesmus species (Huss et al., 1999) and is also known to produce algaenan (Burczyk et al., 1999; Derenne et al., 1992; Versteegh and Blokker, 2004). Because we were unable to identify this exact strain of Chlorella fusca used for algaenan extraction in the Derenne et al. and Burczyk et al. studies, we did not include it in our phylogenetic analysis. Likewise, Chlorella vacuolatus CCAP 211-8b was found to produce algaenan (Derenne et al., 1992) and has since been renamed Scenedesmus vacuolatus; it groups with all other Scenedesmus in Fig. 3. The closely related genera Pediastrum, Sorastrum and Tetraedron all produce algaenan and are, in turn, closely related to Scenedesmus. Only one sequence of Pediastrum was available for the phylogenetic analysis, but four other species are known to produce algaenan. All species of Pediastrum grouped together in our analyses. The prevalence of algaenan in this group of 
genera suggests that more detailed investigation of algaenan production within these groups would be informative.

The phylogenetic relationships among algaenan producers in the Trebouxiophyceae are not as clearcut. Only two of seven strains of Chlorella within the Trebouxiophyceae are algaenan producers; however, the two algaenan producing strains do group with Nanochlorum eukaryotum, another algaenan producer. Botryococcus braunii strains (races A, B, and L) also fall within this group and are known to produce abundant algaenan.

To test the hypothesis that algaenan serves as a protective compound, reinforcing cell walls and zygospores (Blokker et al., 1999; Graham and Wilcox, 2000; Versteegh and Blokker, 2004) and conferring resistance to environmental stress (Allard and Templier, 2000; Versteegh and Blokker, 2004), we targeted terrestrial, stress-tolerant algal strains as well as species that are closely related to land plants and known to be resistant to desiccation. A number of the strains analyzed here come from extreme environments, such as hot and cold deserts, but there does not appear to be a strong relationship between tolerance of environmental extremes and algaenan production. Terrestrial algae are subjected to greater UV stress than aquatic taxa and must be highly desiccation resistant; such algae are known to have exceptionally thick cell walls, but not all produce algaenan. Specifically, of the seven desert species tested, only Scenedesmus deserticola was found to produce the biopolymer. Likewise, algaenan appears to be absent from desiccation-tolerant streptophytes. Further analyses are desirable, as our sampling of marine chlorophytes and ulvaphytes was minimal, but to date, none of these taxa has been shown to produce algaenan.

Our current understanding suggests that algaenan-producers do not represent the majority of green algae, nor do they include the groups most likely to contribute large amounts of biomass 
to large marine organic geochemical sinks. There are numerous examples of correlation between green algae and freshwater kerogens, the Messel Shale and the Queensland oil shale for example, and we do not discount the possibility that green algae are a principal source of algaenan in these kerogens (Goth et al., 1988; Boreham et al., 1994). That stated, the majority of Paleozoic kerogens come from marine deposits

The most abundant green algae in modern oceans are the Prasinophyceae. Prasinophytes are a paraphyletic basal plexus of green algae (Fawley et al., 2000), and all are unicellular and lack cell walls, with the exception of the reproductive phycoma stage of a few genera and resting spores. Because algaenan is linked to the cell walls of algae, the prasinophytes were not considered likely candidates for its production. Nonetheless, we tested for the presence of algaenan in the phycomata of a Halosphaera sp. and did not find an aliphatic biopolymer signature (Kodner, 2007). Because these phycomata are considered to be the precursors of organic walled microfossils such as Tasmanites, this suggests that the aliphatic signature in these fossils is not original. In addition to prasinophytes, we also found no trace of aliphatic biopolymer in the common marine ulvaphyte Ulva enteromorpha. Further surveys within the prasinophytes and marine Chlorophyceae will provide more definitive tests of the hypothesis that green algae constitute likely candidates for the source of algaenan in ancient marine rocks, but current data provide little support this idea. In this regard, cyst-forming prasinophytes merit further attention.

\subsection{Physiological insights from phylogenetic assessment of algaenan producers}

Some of the observed phylogenetic pattern could be explained by physiological differences in cultured organisms. In a notable example, extractions of two different strains of 
Chlorella sorokiniana gave different results. Our phylogeny confirms that they are the same species or sub-species; the low bootstrap support is a function of a short sequence for CCAP $211-8 \mathrm{k}$, and is not reflective of confidence in the branching pattern or branch lengths. Where sequences overlap, the strains are identical. Strain UTEX 1230 produced algaenan when harvested during log growth (Zleibor et al., 1988) while CCAP 211-8k did not when harvested after 30 days. The growth phase of the culture was not identified, although it was likely stationary phase (Burczyk et al., 1999). Although two different extraction methods were used in the algaenan analysis, CCAP 211-8k was subjected to the milder extraction (acid hydrolysis in 6 $\mathrm{N} \mathrm{HCl}$, but without a saponification step) and would be less likely to produce a negative result as an artifact of processing.

In contrast, an example from Botryococcus braunii (race L), examined at different phases of growth, (day 5, day 9 and day 21 of culturing) produced similar algaenan throughout the growth cycle. Similarly, the monomeric composition of algaenan from Tetraedron minimum was identical in two separate studies that cultured the same species on different growth media and in different laboratories (Blokker et al., 1998) and is very similar to Tetraedron minimum algaenan analyzed by Goth et al. (1988). Standardization of culturing conditions and extraction methods will be necessary in further surveys for algaenan production. Experimentation with culture conditions may also uncover a well supported physiological role for algaenan.

Another important consideration that has not been addressed experimentally is the biosynthesis of this biopolymer and its potential metabolic costs. Studies of the biosynthetic pathway to algaenan are very limited. Investigations of the intermediates in strains of Botryococcus braunii showed that the building blocks are long-chain alkyl moieties in the form of polyunsaturated $\alpha, \omega$-dialdehydes, which then condense to polyacetals. These undergo further 
condensation-polymerization reactions with triterpene or tetraterpene diols (Metzger et al., 2008; Metzger et al., 2007). However, it is unknown whether the assembly of algaenan is an active or passive process. Determining patterns of its production across a diversity of organisms will be difficult and likely superficial until considerably more is known about its physiology and biosynthesis.

\section{Conclusions}

\subsection{Algaenan as a geomacromolecule and biomarker for green algae}

The identification of algaenan in the geologic record is based mostly on the link between the aliphatic nature of the preserved organic material and the aliphatic nature of some algal biopolymer (van Bergen, 2004). Algaenan appears to have diverse and convergent biosynthetic sources, but within the green algae may be limited to a phylogenetically restricted group dominated by freshwater taxa. Considering analytical difficulties, the limited diagnostic features of algaenan, the known taphonomic origin of some aliphatic signatures, and limited distribution of algaenan production in modern organisms, algaenan should be interpreted with great caution as a geomacromolecule and a biomarker. It now seems clear that plant and animal fossils, which had living counterparts devoid of algaenan, can have chemical compositions with all the known

attributes of an algaenan (Gupta et al., 2007a; Gupta et al., 2006a; Gupta et al., 2006b; Gupta et al., 2007c).

A number of freshwater kerogens show an aliphatic algaenan-like signature alongside morphological fossils of green algae known to produce algaenan (Boreham et al., 1994; de Leeuw et al., 2006; Derenne et al., 1994; Goth et al., 1988). As microanalytical techniques become more specific, the aliphatic compounds in kerogen may become more precisely linked to 
specific microfossils (Blokker et al., 2006), but this may be limited to freshwater environments and would not explain aliphatic kerogen from marine environments.

The role of algaenan as a precursor of petroleum remains unclear. The Neoproterozoic radiation of algae, and especially chlorophytes, corresponds in time with the oldest known commercial petroleum deposits (Knoll et al., 2007). Given the findings presented here, and the relative rarity of algaenan production discovered so far, it remains unclear whether there is any specific relationship between the selective preservation of algaenan and the formation of oilprone kerogen, especially in the marine realm. Algaenan in Paleozoic marine kerogen could reflect biosynthesis by some as yet unrecognized marine algae, a greater representation in ancient oceans of algaenan-producing chlorophyte clades today limited to non-marine environments, or diagenetic formation of an algaenan-like geopolymer within marine sediments. It also remains in doubt whether the evolution of selectively preserved biopolymers such as algaenan had any significant effect on long-term carbon burial and, hence, the geological trajectory of the carbon cycle.

\subsection{The nature of algaenan as a biological compound}

As discussed above, much remains to be learned about the distribution of algaenan, its putative physiological role and its biosynthesis. It is especially important to determine whether or not that the biosynthesis is an enzyme-mediated process that can be traced via the DNA that codes for the proteins involved. Biosynthetic studies will also begin to uncover the physiological role of algaenan, when carried out in conjunction with further experimentation with culture condition. In general, a greater understanding of the biology of algaenan will enhance its role as a biomarker and its possible geologic relevance. 


\section{Acknowledgements}

The authors gratefully acknowledge the help and advice of numerous colleagues during the course of this work. We especially thank Jan de Leeuw, Stefan Schouten, and an anonymous reviewer for providing insightful comments. Gordon Love and Carolyn Colonero provided help and advice in the laboratory. Louise Lewis and Zoe Cardon of the University of Connecticut provided cultures, primers, culturing advice and helpful discussion. RBK acknowledges support from the NSF GRF while AHK and RES were supported by grants from the National Science Foundation (EAR 0420592) and the NASA Astrobiology Institute.

\section{References}

Adl, S.M., Simpson, A.G.B., Farmer, M.A., Andersen, R.A., Anderson, O.R., et al.., 2005. The new highter level classification of eukaryotes, with emphasis on the taxonomy of protists. Journal of Eukaryotic Microbiology, 52, 399-451.

Allard, B., Rager, M., Templier, J., 2002. Occurence of high molecular weight lipids (C80+) in the trilaminar outer cell walls of some freshwater microalgae. A reappraisal of algaenan structure. Organic Geochemistry, 33, 789-801.

Allard, B., Templier, J., 2000. Comparison of neutral lipid profile of various trilaminar outer cell wall (TLS)- containing microalgae with emphasis on algaenan occurrence. Phytochemistry, 54, 369-380.

Behar, F., Derenne, S., Largeau, C., 1995. Closed pyrolyses of the isoprenoid algaenan of Botryococcus braunii, L race: geochemical implications for derived kerogens. Geochimica et Cosmochimica Acta, 59(14), 2983-2997.

Berner, R.A., 1989. Biogeochemical cycles of carbon and sulphur and their effect on atmospheric oxygen over Phanerozoic time. Paleogeography, Paleoclimatology, and Paleoecology, $73,97-122$.

Bertheas, O., Metzger, P., Largeau, C., 1999. A high molecular weight complex lipid, aliphatic polyaldehyde tetraterpenediol polyacetal from Botryococcus braunii (L race). Phytochemistry, 50(1), 85-96.

Biomatters, 2007. Geneious (Ed. by B. Ltd.). www.biomatters.com.

Blokker, P., 2000. Structural analysis of resistant polymers in extant algae and ancient sediments. Geologica Ultratrajectina, 193, 1-145. 
Blokker, P., Schouten, S., De Leeuw, J.W., Damste, J.S.S., van den Ende, H., 2006. A comparative study of fossil and extant algaenans using ruthenium tetraoxide degradation. Geochemica et Cosmochimica Acta, 64(12), 2055-2065.

Blokker, P., Schouten, S., de Leeuw, J.W., Sinninghe Damsté, J.S., van den Ende, H., 1999. Molecular structure of the resistant biopolymer in zygospore cell walls of Chlamydomonas monoica. Planta, 207(4), 539-543.

Blokker, P., Schouten, S., van den Dnde, H., de Leeuw, J.W., Hatcher, P., Damste, J.S.S., 1998. Chemical structure of algaenans from the fresh water algae Tetraedron minimum, Scenedesmus communis and Pediastrum boryanum. Organic Geochemistry, 29(5), 1453-1468.

Boreham, C., Roksandic, Z., Dowling, L., Hutton, A., Summons, R., 1994. Chemical, molecular and isotopic differentiation of organic facies in the Duaringa oil shale deposit, Queensland, Australia. Organic Geochemistry 21, 685-712.

Briggs, D., Kear, A., Baas, M., de Leeu, J., Rigby, S., 1995. Decay and composition of the hemichordate Rhabdopleura: implications for the taphonomy of graptolites. Lethaia, 28(1), $15-23$.

Burczyk, J., Smietana, B., Terminska-Pabis, K., Zych, M., Kowalowski, P., 1999. Comparison of nitrogen content amino acid composition and glucosamine content of cell walls of various chlorococcalean algae. Phytochemistry, 51, 491-497.

Cavalier-Smith, T., 1998. A revised six-kingdom system of life. Biological Reviews of the Cambridge Philosophical Society, 73, 203-266.

Clamp, M., Cuff, J., Searle, S.M., Barton, J.G., 2004. The Jalview Alignment Editor. Bioinformatics, 20, 426-427.

de Leeuw, J.W., 2007. On the origin of sedimentary aliphatic macromolecules: A comment on recent publications by Gupta et al. Organic Geochemistry, 38(9), 1585-1587.

de Leeuw, J.W., Versteegh, G.J.M., van Bergen, P.F., 2006. Biomacromolecules of algae and plants and their fossil analogues. Plant Ecology, 182(1), 209-233.

Derenne, S., Largeau, C., Behar, F., 1994. Low polarity pyrolysis products of Permian to Recent Botryococcus-rich sediments: First evidence for the contribution of an isoprenoid algaenan to kerogen formation. Geochimica et Cosmochimica Acta, 58(17), 3703-3711.

Derenne, S., Largeau, C., Casadevall, E., Berkaloff, C., Rousseau, B., 1991. Chemical evidence of kerogen formation in source rocks and oil shales via selective preservation of thin resistant outer walls of microalgae: Origin of ultralaminae. Geochimica et Cosmochimica Acta, 55(4), 1041-1050.

Derenne, S., Largeau, C., Hatcher, P.G., 1992. Structure of Chlorella fusca algaenan: Relationships with ultralaminae in lacustrine kerogens; species- and environment-dependent variations in the composition of fossil ultralaminae. Organic Geochemistry, 18(4), 417-422.

Fawley, M.W., Yun, Y., Qin, M., 2000. Phylogenetic analysis of 18s rDNA sequences reveal a new coccoid lineage of the Prasinophyceae (Chlorophyta). Journal of Phycology, 36, 387-393.

Felsenstein, J., 2005. PHYLIP (Phylogeny Inference Package). Department of Genome Sciences, University of Washington.

Gelin, F., Boogers, I., Noordeloos, A.A.M., Damste, J.S.S., Hatcher, P.G., de Leeuw, J.W., 1996. Novel, resistant microalgal polyethers: An important sink of organic carbon in the marine environment? Geochimica et Cosmochimica Acta, 60(7), 1275-1280.

Gelin, F., de Leeuw, J.W., Damste, J.S.S., Derenne, S., Largeau, C., Metzger, P., 1994. The similarity of chemical structures of soluable aliphatic polyaldehyde and insoluable algaenan 
in the green microalga Botryococcus braunii race A as revealed by analytical pyrolysis. Organic Geochemistry, 21(5), 423-435.

Goth, K., de Leeuw, J.W., Puttmann, W., Tegelaar, E.W., 1988. Origin of Messel Shale kerogen. Nature, 336, 759-761.

Graham, L.G., Wilcox, L.W., 2000. Algae. Prentice-Hall, Upper Saddle River, NJ.

Guindon, S., Lethiec, F., Duroux, P., Gascuel, O., 2005. Phyml Online--a web server for fast maximum likelihood-based phylogenetic inference. Nucleic Acids Reserach, 33(W5579).

Guiry, M.D., Guiry, G.M., 2008. AlgaeBase. National University of Ireland, Galway.

Gupta, N.S., Briggs, D.E.G., Collinson, M.E., Evershed, R.P., Michels, R., Pancost, R.D., 2007a. Molecular preservation of plant an insect cuticles from the Oligocene Enspel formation, Germany: Evidence against derivation of aliphatic polymer from sediment. Organic Geochemistry, 38, 404-418.

Gupta, N.S., Collinson, M.E., Briggs, D.E.G., Evershed, R.P., Pancost, R.D., 2006a. Reinvestigation of the occurrence of cutan in plants: implications for the leaf fossil record. Paleobiology, 32, 432-449.

Gupta, N.S., Michels, R., Briggs, D.E.G., Collinson, M.E., Evershed, R.P., Pancost, R.D., 2007b. Experimental evidence for the formation of geomacromolecules from plant leaf lipids. Organic Geochemistry, 38(1), 28-36.

Gupta, N.S., Michels, R., Briggs, D.E.G., Evershed, R.P., Pancost, R.D., 2006b. The organic preservation of fossil arthropods: and experimental study. Proceedings of the Royal Society of London B, 273, 2777-2783.

Gupta, N.S., Tetile, O.E., Briggs, D.E.G., Pancost, R.D., 2007c. The fossilization of eurypterids: A result of molecular transformation. Palaios, 22, 439-447.

Handa, S., Nakahara, M., Tsubota, H., Denguchi, H., Nakano, T., 2003. A new arial alga, Stichiococcus ampulliforimis sp. nov. (Trebouxiophyceae, Chlorophyta) from Japan. Phycological Research, 51(3), 203-210.

Hedges, J.I., 1995. Sedimentary organic matter preservation: an assessment and speculative synthesis. Marine Chemistry, 49, 81-115.

Huss, V.A.R., Frank, C., Hartmann, E.C., Hirmer, M., Kloboucek, A., Seidel, B.M., P., W., Kessler, E., 1999. Biochemical taxonomy and molecular phylogeny of the genus Chlorella sensu lato (Chlorophyta). Journal of Phycology, 35, 587-598.

Kodner, R.B., 2007. Using modern analogs to investigate the microfossil and molecular fossil record of eukaryotes: examples from animals and algae. In: Department of Organismic and Evolutionary Biology, PhD. Harvard University, Cambridge, MA.

Kodner, R.B., Graham, L.G., 2001. High-temperature, acid-hydrolyzed remains of Polytrichum (Musci, Polytrichaceae) resemble enigmatic Silurian-Devonian tubular microfossils. American Journal of Botany, 88(462-466).

Kroken, S.M., Graham, L.G., Cook, M.E., 1996. Occurrence and evolutionary significance of resistant cell walls in charophytes and bryophytes. American Journal of Botany, 83(12411254).

Kuypers, M., Blokker, P., Hopmans, E., Kinkel, H., Pancost, R., Schouten, S., Sinnighe-Damste, J., 2002. Archaeal remains dominate marine organic matter from the early Albian oceanic anoxic event 1b. Paleogeography, Paleoclimatology, Paleoecology, 185, 211-234.

Metzger, P., Rager, M., Fosse, C., 2008. Braunicetals: Acetals from condensation of macrocyclic aldehydes and terpene diols in Botryococcus braunii. Phytochemistry, 69(12), 2380-2386. 
Metzger, P., Rager, M., Largeau, C., 2007. Polyacetals based on polymethylsualene diols, precursors of algaenan in Botryococcus braunii race B. Organic Geochemistry, 38, 566-581.

Montsant, A., Zarka, A., Boussiba, S., 2001. Presence of a nonhydrolyzable biopolymer in the cell wall of vegetative cells and astaxanthin-rich cysts of Haematococcus pluvialis (Chlorophyceae). Marine Biotechnology, 3(6), 515-521.

Qiu, Y., Li, 1., Wang, B., Chen, Z., Dombrovska, O., Lee, J., Kent, L., Li, R., Jobson, R., Hendry, T., Taylor, D., Testa, C., Ambros, M., 2007. A nonflowering land plant phylogeny inferred from nucleotide sequences of seven chloroplast mitochondrial, and nuclear genes. International Journal of Plant Sciences, 168(5), 691-708.

Qiu, Y., li, L., Wang, B., Chen, Z., Knoop, V., Growth-Malonek, M., Dombrovska, O., Lee, J., Kent, L., Rest, J., Estabrook, G., Hendry, T., Taylor, D., Testa, C., Ambros, M., CrandallStotler, B., Duff, R., Stech, M., Frey, W., Quandt, D., Davis, C., 2006. The deepest divergences in land plants inferred from phylogenomic evidence. Proceedings of the $\mathrm{Na}$ tional Academy of Sciences, USA, 103(42), 15511-15516.

Salmon, E., Behar, F., Lorant, F., Hatcher, P.G., Metzger, P., Marquarie, P., 2009. Thermal decomposition process in algaenan of Botryococcus braunii race L. Part 1: experimental data and structural evolution. Organic Geochemistry, in press.

Salmon, E., van Duin, A.C.T., Lorant, F., Marquarie, P., Goddard III, W.A., 2008. Thermal decomposition process in algaenan of Botryococcus braunii race L. Part 2: Molecular dynamics simulations using the ReaxFF reactive force field. Organic Geochemistry, in press.

Schouten, S., Moerkerken, P., Gelin, F., Baas, M., de Leeuw, J.W., Damste, J.S.S., 1998. Structural characterization of alipatic, non-hydrolyzable biopolymers in freshwater algae and a leaf cuticle using ruthenium tetroxide degradation. Phytochemistry, 49(4), 987-993.

Senousy, H., Gordon, W.B., Hack, E., 2004. Phylogenetic placement of Botryococcus braunii (Trebouxiouphyceae) and Botryococcus sudeticus isolate UTEX 2629 (Chlorophyceae). Journal of Phycology, 40(2), 412-423.

Shoup, S., Lewis, L.A., 2003. Polyphyletic origin of parallel basal bodies in swimming cells of chlorophycean green algae (Chlorophyta). Journal of Phycology, 39, 789-796.

Tegelaar, E.W., de Leeuw, J.W., Derenne, S., Largeau, C., 1989. A reappraisal of kerogen formation. Geochemica et Cosmochimica Acta, 53, 3103-3106.

Templier, J., Largeau, C., Casadevall, E., Berkaloff, C., 1992. Chemical inhibition of resistant biopolymer in outer walls of the A and B races of Botryococcus braunii. Phytochemistry, 31(12), 4097-4104.

van Bergen, P.F., 2004. Structural biomacromolecules in plants: what can be learnt from the fossil record?, Evolution of Plant Physiology, pp. 133-154. Elsevier, Amsterdam.

Versteegh, G.J.M., Blokker, P., 2004. Resistant macromolecules of extant and fossil microalgae. Phycological Research, 52(4), 325-339.

Versteegh, G.J.M., Blokker, P., Wood, G.D., Collinson, M.E., Damsté, J.S.S., de Leeuw, J.W., 2004. An example of oxidative polymerization of unsaturated fatty acids as a preservation pathway for dinoflagellate organic matter. Organic Geochemistry, 35(10).

Zleibor, J.L.J., Romankiw, L., Hatcher, P.G., Colwell, R.R., 1988. Comparative analysis of the chemical composition of mixed and pure cultures of green algae and their decomposed residues by $13 \mathrm{C}$ nuclear magnetic resonance spectroscopy. Applied and Environmental Microbiology, 54, 1051-1060. 


\section{Figure Captions}

Fig. 1. Total ion current (TIC) traces of successive hydrolysis steps in algaenan extraction of Scenedesmus deserticola SN2-1. TIC generated using pyrolysis gas chromatography-mass spectrometry (py-GC-MS). This series represents sequential algaenan purification steps. A-C show TIC, D-F show extracted $\mathrm{m} / z$ 83+85 chromatograms. A and D are residual biomass after $12 \mathrm{~N}$ TFA hydrolysis, $\mathrm{B}$ and $\mathrm{E}$ after $6 \mathrm{~N}$ HCL hydrolysis and $\mathrm{C}$ and $\mathrm{F}$ after saponification

Fig. 2. TIC traces from the py-GC-MS analysis of Scenedesmus algaenan in this study.A. Scendesmus acuminatus UTEX 415 B. Scenedesmus platydiscus UTEX 2547 C. Scenedesmus acutiformis UTEX 416 D. Scenedesmus obliqus UTEX 1450. All algaenan samples from this group display a similar alkane/alkene distribution, although the dominant alkane/alkene of the doublet is variable, the longest alkane/alkene chain length being $\mathrm{C}_{26}$.

Fig. 3. Phylogeny of green algae tested for presence of algaenan. 3A. Consensus maximum likelihood phylogeny of $18 \mathrm{~S}$ SSU rDNA of Chlorophyta tested for algaenan. Identical topologies recovered with PHYML and PHYLIP analysis with 100 boostrapped datasets. Bootstrap values reported as PHYML/PHYLIP. Missing number means bootstrap value below 50; * indicates sequence generated in this study. Taxa in red produce algaenan. 3B. Representation of the diversity and abundance of taxa at the class level in the green algae. White numbers are numbers of species within the class represented in algaebase (Guiry and Guiry, 2008), blue numbers are number of species tested for algaenan, red numbers are numbers of species that produce algaenan. *Data on species from some morphologically recognized classes were grouped together. Ulvaphyceae includes the Bryopsidophyceae and the Prasinophyceae include the Pedinophyceae and the Nephroselmidophyceae for the Figure. 


\begin{tabular}{|c|c|c|c|}
\hline Species definition & Strain & Accession \# & Isolation/culture media \\
\hline Botryococcus braunii & Ayame & AJ581910.1. & $\mathrm{FW} / \mathrm{FW}$ \\
\hline Botryococcus braunii & Songkla Nakarin & AJ581911.1. & FW/FW \\
\hline Botryococcus braunii & Titicaca & AJ581912.1. & FW/FW \\
\hline Botryococcus braunii & CCAP 807/1 & AJ581913.1. & FW/FW \\
\hline Botryococcus sudeticus & UTEX 2629 & AJ581914.1. & FW/FW \\
\hline Bracteococcus sp. & BC2-1 & AF516676.1. & Desert crust/FW \\
\hline Chlamydomonas reinhardtii & CBS & this study & soil/FW \\
\hline Chlorella ellipsoidea & IAM C-87 & D13324.1. & FW/FW \\
\hline Chlorella ellipsoidea & UTEX 20 & DQ644520.1 & FW/FW \\
\hline Chlorella emersonii & CCAP 211/8p & This study & \\
\hline Chlorella marina RK83 & CCAP $211 / 27$ & This study & Marine/SW \\
\hline Chlorella minutissima & CCAP 211-52 & AF360745.1 & FW/FW \\
\hline Chlorella multissima RK88 & UTEX 2341 & This study & Marine/FW \\
\hline Chlorella' saccharophila & CCAP 211-1a & EF030570.1. & FW/FW \\
\hline Chlorella sorokiniana & UTEX 1230 (relative of CCAP & This study & FW/FW \\
\hline Chlorella sorokiniana & CCAP211/8k (relative of UTEX & This study & FW/FW \\
\hline Chlorella vulgaris & CBS & This study & FW/FW \\
\hline Chlorococcum sp? RK30 & CCMEE 176 & This study & Cold desert rock/FW \\
\hline Chlorosarcinopsis gelatinosa & SEV2-VF1 & AF516678.1. & Desert crust/FW \\
\hline Chlorosarcinopsis sp?(RK29) & CCMEE 174 & This study & Cold desert endolith/FW \\
\hline Coelastrum reticulatum & SAG 8.81 & AF388382.1 & FW/FW \\
\hline Dunaliella tertiolecta & CCMP 364 & DQ009772.1 & Marine/SW \\
\hline Enteromorpha intestinalis & & AJ000040.1. & Marine/SW \\
\hline Haematococcus pluvialis & UTEX 2505 & AF159369.1. & FW/FW \\
\hline Nanochlorum eucaryotum & Mainz 1 & X06425.1. & Marine/SW \\
\hline Pediastrum boryanum var. & UTEX LB 470 & AY663035.1. & FW/FW \\
\hline Scenedesmus acuminatus RK74 & UTEX 415 & This study & FW/FW \\
\hline Scenedesmus acutiformis RK75 & UTEX 416 & This study & FW/FW \\
\hline Scenedesmus bajacalifornicus & LG2VF16 & AF513372.1. & Desert crust/FW \\
\hline Scenedesmus communis & UTEX 76 & X73994.1. & FW/FW \\
\hline Scenedesmus deserticola & BCP-SNI-2 & AY510462.1. & Desert crust/FW \\
\hline Scenedesmus deserticola & BCP-HAF2-VF10 & AY510464.1. & Desert crust/FW \\
\hline Scenedesmus obliquus & UTEX 1450 & AJ249515.1. & FW/FW \\
\hline Scenedesmus pannicus RK 86 & UTEX 77 & This study & FW/FW \\
\hline Scenedesmus vacuolatus & Sag 211-8b & X56104.1. & FW/FW \\
\hline Sorastrum spinulosum strain & UTEX LB 2452 (relative SAG & AY663041.1. & FW/FW \\
\hline Stichococcus bacillaris & SAG 397-1b & AJ416107.1. & Brackish/FW \\
\hline Tetraedron minimum strain & UTEX LB 1367 & AY663042.1. & FW/FW \\
\hline Trentepohlia sp. & UTEX 1227 & AY052569.1. & From lichen/FW \\
\hline
\end{tabular}


Sequence Name Sequence

18sFsequencing
18sRsequencing
B0_PS2_L_chloro
B0_PS2_R_chloro
18s70f
$18 s 2420 r$
SSUi
$284 \mathrm{~F}$
$373 \mathrm{C}$
C18G
N18G
$1057 f$
$1081 \mathrm{r}$
C18H
$1243 \mathrm{R}$
$\mathrm{C} 18 \mathrm{~J}$

Reference

TCG TAG TTG GAT TTC GGG TGG GTT TAC CGG AAT CAA CCT GAC AAG GCA TAA ACG ATG CCG ACT AGG GAT TGG CCC AGA ACA TCT AAG GGC ATC ACA TGA AAC TGC GAA TGG CTC TAG GAG CGA CGG GCG GTG TG TGG TTG ATC CTG CCA GTA G GCG ATG TIT CAT TCA AAT TTC TG GAT TCC GGA GAG GGA GCC TG TGG CAC CAG ACT TAC CCT AGG GCA AGT CTG GTG CCA G GAT GAC TCC GCC AGC ACC TTA TG CTC ATA AGG TGC TGG CGG AGT CCT CCG TCA ATT CCT TTA GTT TCA GC AGA GCT CTC AAT CTG TCA

This study This study This study This study This study This study Shoup and Lewis, 2003 Lewis lab Booton et al., 1998

Shoup and Lewis, 2003 Shoup and Lewis, 2003 Lewis lab Lewis lab Shoup and Lewis, 2003 Shoup and Lewis, 2003 TCT AAG GGC ATC ACA GAC CTG TTA TTG Shoup and Lewis, 2003 
Glaucophytes

Cyanophora paradoxa

UTEX + CCMP

Glaucocystis nosticarium

UTEX + CCMP

Green Algae

Chlorophyceans

Botryococcus braunii (L race)

Bracteacoccus sp.

Chlamydomonas reinhardtii

yes

Chlorococcoidiopsis sp.? RK30

BC2-1

CBS

Chlorophycean sp.

CCMEE 171

edesmus acuminatus RK74

UTEX 416

Scenedesmus deserticola

BCP-SNI-2

BCP-HAF2-VF10

UTEX 1450

Scenedesmus obliquus

Scenedesmus sp.

LG2VF16

Scenedesmus platydiscus RK72 UTEX2457

yes

yes

yes

yes

yes

-

yes

Trebouxiophyceans

Chlorosarcinopsis sp.?(RK29) CCMEE 174

Chlorella vulgaris

CBS

Ulvaphyceans

Enteromorpha intestinalis

CBS

Charophyceans

Coleochaete sucatta

CBS

Cylindrocystis brebsonii

LG2 VF30

Zygnema sp.?

CBS

Red Algae

Acrochaetium

CBS

Land Plants (Liverworts)

Conocephelum

Monoclea fosterii

Marcantia polymorpha

Porella

Riccia
New Hampshire/Kentucky

collected in NX

Kentucky

CBS

CBS 
Figure 1
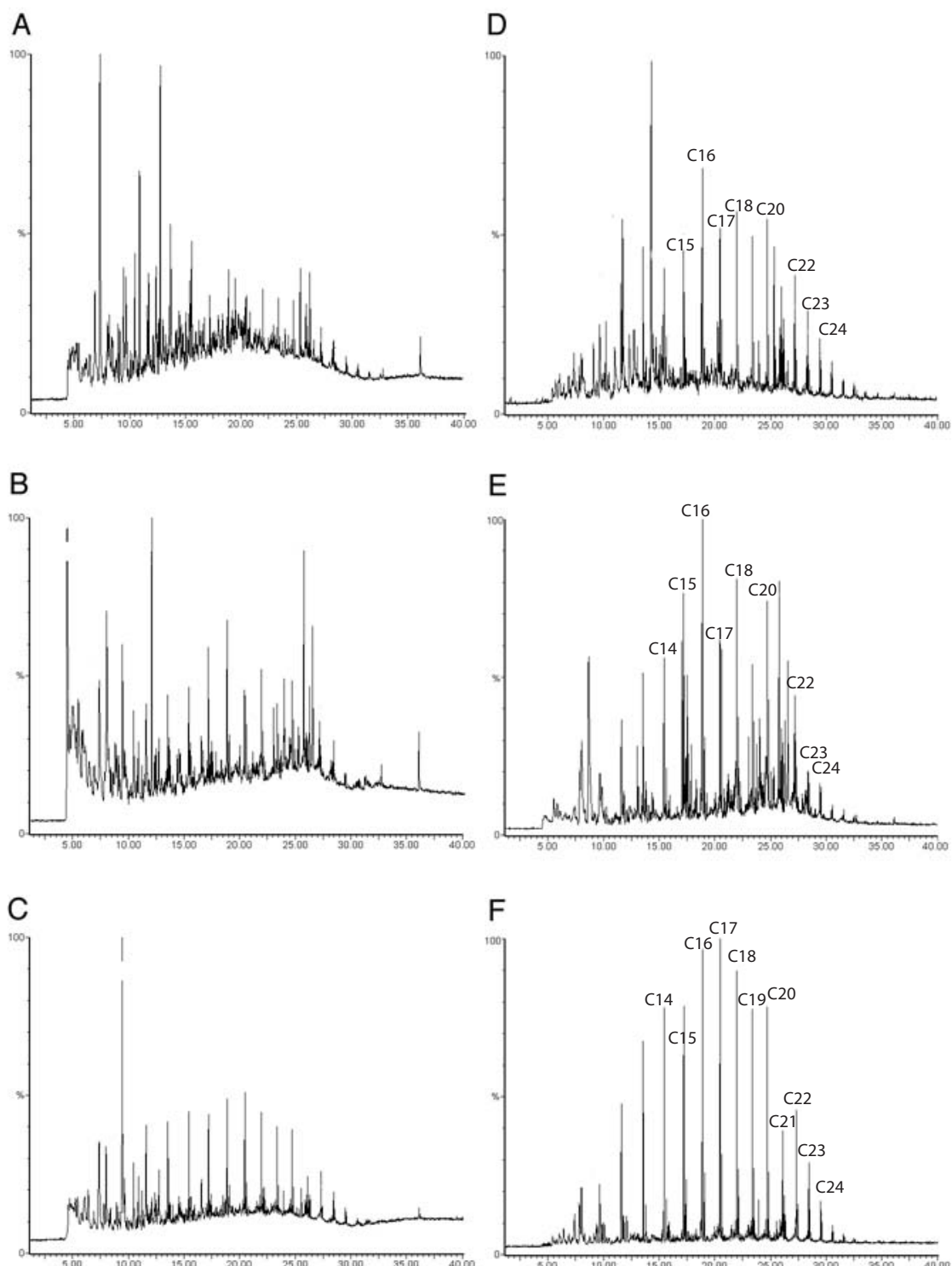
Figure 2

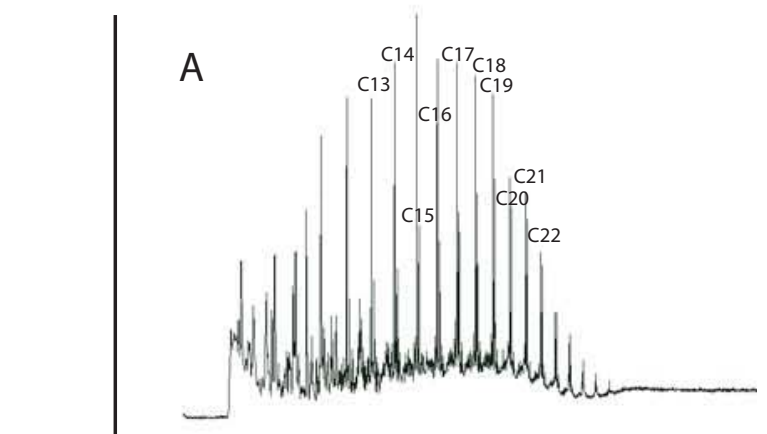

B

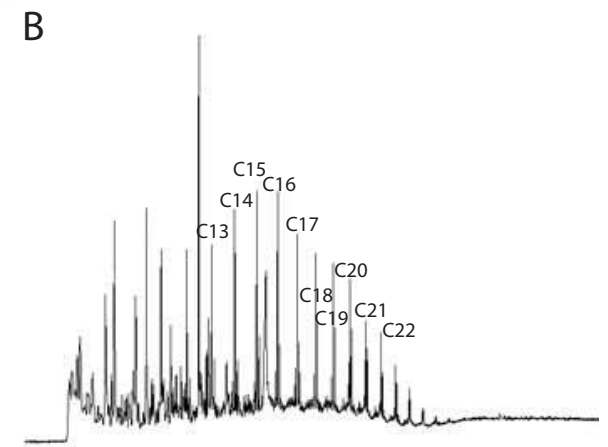

C

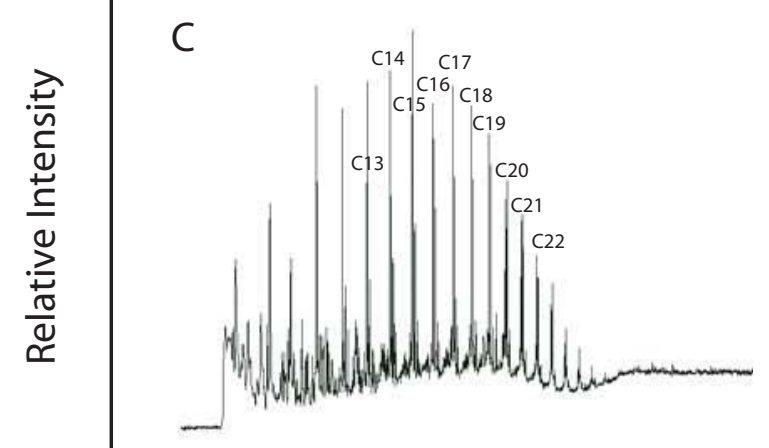

D

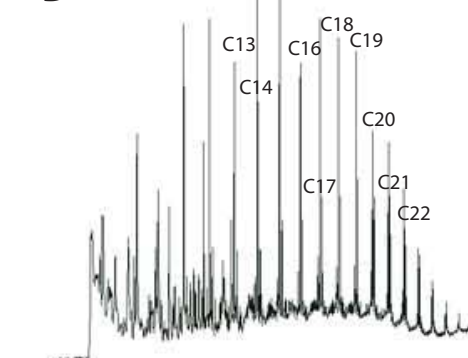

Time 


\section{Figure 3

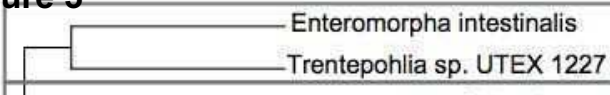

Trentepohlia sp. UTEX 1227
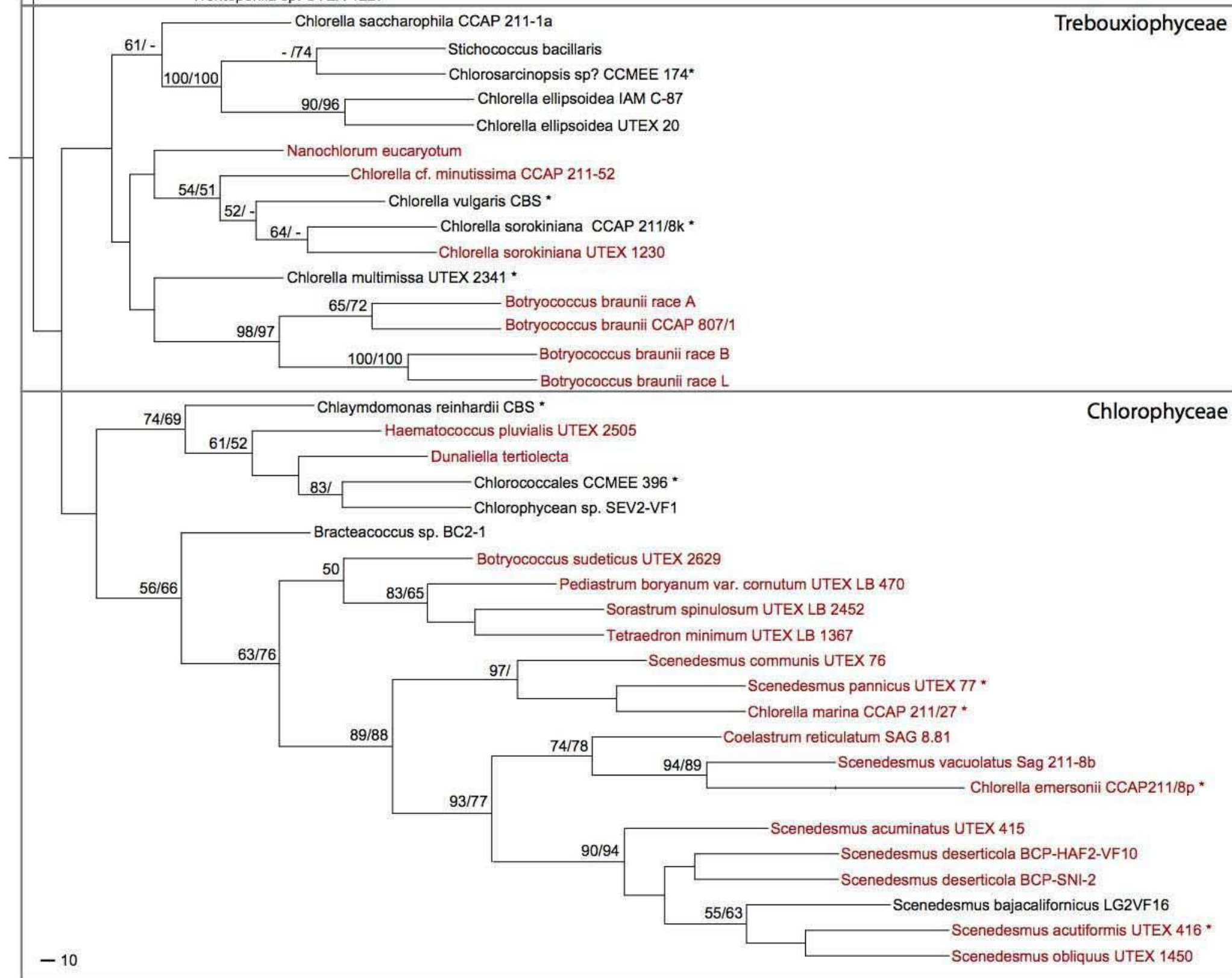

B

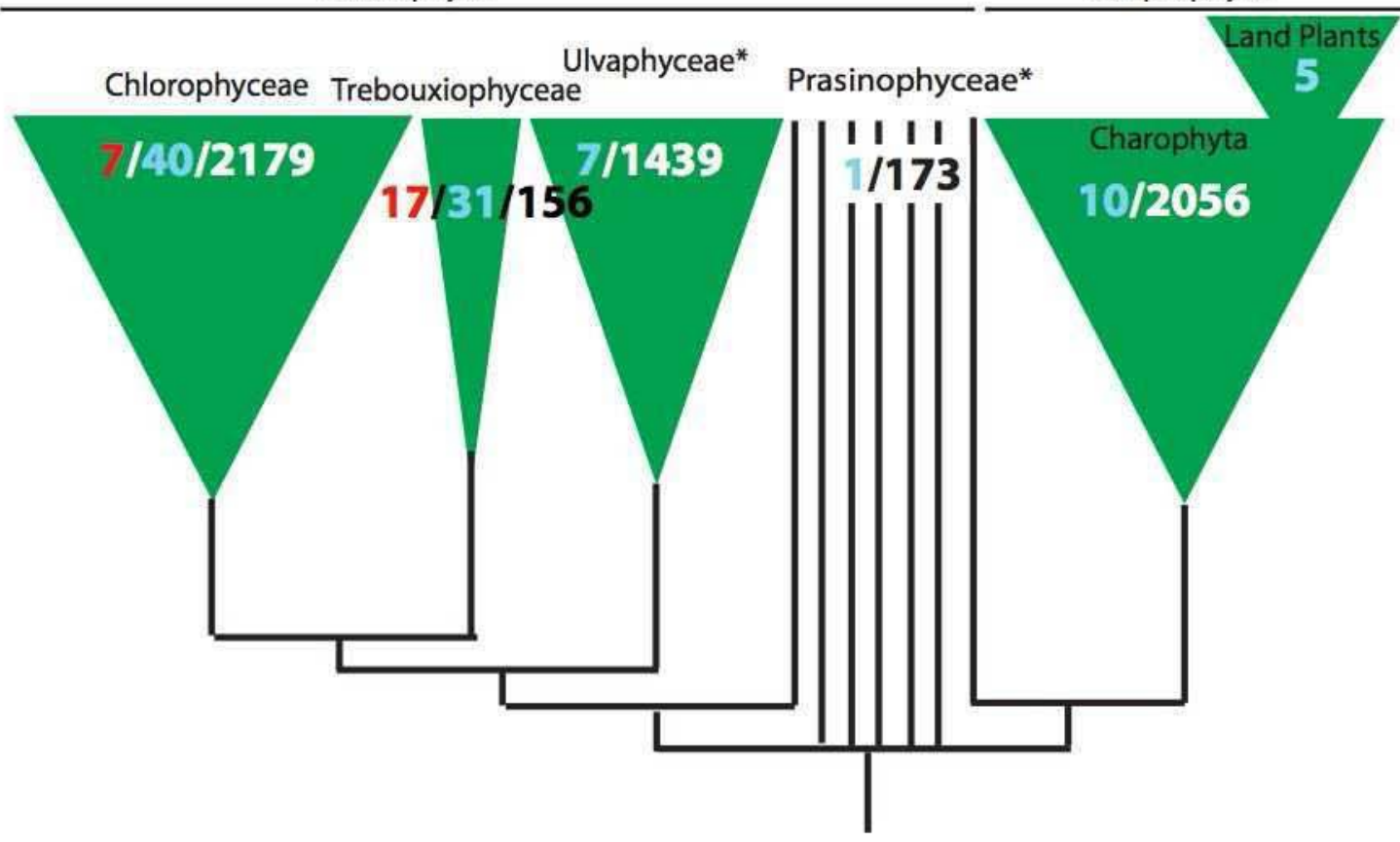

